\title{
Basic techniques for transgenesis
}

\author{
I. Wilmut and A. J. Clark \\ AFRC Institute of Animal Physiology and Genetics Research, Roslin, Midlothian EH25 9PS, UK
}

Keywords: gene transfer; gene modification; gene expression; livestock; transgenic animal

\section{Introduction}

A major change in biological research was heralded by the development of methods for the manipulation of the mammalian germ line. The ability to modify genes permits analysis of the control of gene expression and of the role of particular gene products at any period in the life cycle. In addition to advantages for research, there are commercial applications for these new procedures, particularly for farm animals.

Two types of germ-line manipulation can be envisaged: gene transfer and gene modification. In the first case a gene (termed a transgene) is added to the genome, whilst in the second an existing gene is modified or destroyed. At present only gene transfer has been achieved in farm animals, but the recent isolation of embryo stem cells from livestock (Notarianni et al., 1990a, b) suggests that gene modification will become possible in these species as it is in mice. This paper will review the presently available methods of gene transfer and their limitations in livestock, before considering the mechanisms that regulate gene expression and the consequences these have for the design of functional transgenes and projects that involve modification to genes.

\section{Germ-line manipulation}

The usual method of gene transfer in mammals involves the direct injection of several hundred copies of the gene into a nucleus in the early embryo (Fig. 1), generally a pronucleus (Brinster et al., 1985). Fertilized eggs are recovered from a donor animal that has been induced to superovulate. Surviving eggs are transferred to recipient females and allowed to develop to term. Three factors make the use of this technique in livestock more difficult than in mice: cytoplasmic vesicles obscure the view of the nuclei, fewer eggs are available, and there is greater variability in the stage of embryo development. Despite these limitations the procedure has been used successfully in sheep (Simons et al., 1988; Murray et al., 1989), cattle (Biery et al., 1988) and pigs (Hammer et al., 1985). In sheep, most pronuclei can be visualized by careful use of differential interference contrast microscopy of untreated eggs. By contrast, in cattle the egg must be centrifuged, typically at $15000 \mathrm{~g}$ for $5 \mathrm{~min}$, before the nuclei can be seen. Centrifugation stratifies the cytoplasm and leaves the nuclei in a clear equatorial layer. Gene transfer by direct injection has several limitations and these will be considered in turn.

The proportion of injected eggs that survive to become live transgenic offspring is small, being 0-4\% in livestock (Simons et al., 1988; Murray et al., 1989; Pursel et al,, 1989). Overall, there is an impression that the proportion in mice is rather higher, being as high as $10 \%$ in experienced hands (Brinster et al., 1985). The mechanism responsible for the integration of the injected genes is not known. When DNA is introduced into a nucleus, incorporation into a chromosome may occur by cross-over between the injected DNA and a site in a chromosome where the same sequences are present. However, there is only one case for which integration of this kind is known to have occurred (Brinster et al., 1989a): when over 10000 eggs were injected with DNA sequences 


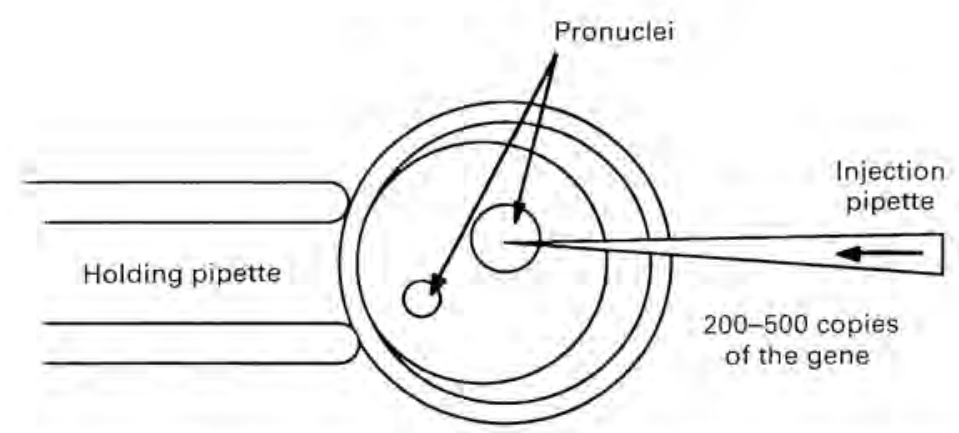

Fig. 1. Gene transfer by direct injection. Embryos are usually recovered from donor females at the pronuclear stage of development. Each embryo is secured upon a holding pipette by suction to allow the introduction of a fine pipette into one of the pronuclei. About $10^{-9} \mathrm{ml}$ DNA solution is expelled, sufficient to cause distension of the pronucleus. In mice the pronucleus can be seen readily, especially if differental interference contrast optics are used, whereas in sheep this is more difficult. In pigs and cattle the embryo must be centrifuged to stratify the cytoplasm and reveal the pronuclei. Embryos which survive microinjection are transferred into foster mothers which are pseudopregnant or synchronized, as appropriate. Following birth of animals derived from injected embryos, DNA is prepared from a sample of tissue or blood and analysed for the presence of the injected sequences.

designed to correct a deletion only 1 of over 500 transgenic mice produced was found to have the fragment incorporated at the site of the endogenous gene. This observation suggests that another mechanism is usually responsible for integration of the transgene. It has been suggested that integration depends upon the injection of fluid causing breakage of chromosomes and the inadvertent inclusion of the transgene during the repair (Palmiter \& Brinster, 1986). While this suggestion is compatible with all of the present observations, it has not been tested directly.

The small proportion of injected eggs that become transgenic young may reflect the facts that many eggs are killed by the act of injection and that integration of the gene is an infrequent event. The act of injection itself is harmful and not all injected eggs are judged worthy of transfer to recipient females. It may be envisaged that, whereas some effects of cellular damage become apparent very quickly, the effects of chromosomal damage occur throughout development. In addition, in some cases, expression of the transgene during prenatal development may also have deleterious effects. While all reports describe the loss of many injected eggs after transfer to recipients, there is considerable variation between reports in the apparent time of the loss. In some cases only about $20 \%$ became morulae or blastocysts (Biery et al., 1988) whereas in others the proportion was $52 \%$ (Walker, 1989). It has been noted that fetal loss occurs throughout gestation (Murray et al., 1989; and our unpublished observations).

The apparent difference between mice and livestock in the proportions of injected eggs that become transgenic young may reflect the fact that the procedures were optimized for use with mouse embryos (Brinster et al., 1985). Comparisons between the livestock species have not been made because of the great cost of the experiments required to detect small differences in the success rate.

One approach to reduce the costs of gene transfer is to use in-vitro culture systems for the production of eggs and the early development of the injected eggs. Methods are now available for the maturation and fertilization of sheep and cattle oocytes in culture (Staigmiller \& Moor, 1984; Parrish et al., 1986). Progress is also being made in the establishment of procedures for the culture of fertilized eggs to the morula or blastocyst stage of development at which they can be transferred to the uterus of recipient females, using non-surgical or laparoscopic methods of transfer which are much less demanding than surgical transfer into the oviduct (Gordon \& Lu, 1990). In principle, this idea is attractive as approximately half the animals required for gene transfer are used as donors, 
but at the present stage of development of the techniques there are significant drawbacks. Not all of the fertilized eggs are capable of normal development to term. Current yields being obtained by commercial groups are not available, but in one large trial rather less than $30 \%$ of fertilized eggs developed to term after using the sheep oviduct to support development to the blastocyst stage (Lu et al., 1988). As a result, it would be necessary to culture considerable numbers of oocytes, more eggs must be injected and there is a need for additional recipients, which reduces the potential saving in animals. In time, this technology will be extremely useful, but further improvements are required.

A second approach to reduce costs is to attempt to identify those embryos in which the gene has integrated before transfer to a recipient. This would involve culture of injected eggs to the morula or blastocyst stage of development. At this time a small number of cells would be removed for analysis. DNA would be extracted from the cells and amplified by the polymerase chain reaction (Saiki et al., 1988). There are several possible methods of detecting the amplified product. If specific primers have been selected then the most efficient procedure is simply to examine ethidium bromidestained gels under ultraviolet light for the presence or absence of DNA bands. However, if experience suggests that non-specific amplification may occur, then specificity may be confirmed by the use of probes, labelled with an isotope or a biological label. Those embryos that have been shown to have a transgene may then be transferred to recipient females. This scheme has not been tested adequately, although research in this area is being undertaken (King \& Wall, 1988; Ninomiya et al., 1989). The value of the procedure will depend upon the proportion of embryos which show a false positive result because of the presence of unintegrated DNA remaining from the time of injection and the proportion of transgenic embryos that die during pregnancy. This approach would not increase the proportion of injected embryos that became transgenic young, but in fact could cause a decrease in this proportion if there were harmful effects of the biopsy. However, it would reduce the requirement for recipient females if embryos were eliminated by the screening procedure. This would be particularly valuable for projects with cattle because of their great cost. An additional test could be applied at the same time to determine the sex of the embryo and allow the transfer of 2 embryos of the same sex to each recipient. This would increase the efficiency of use of recipients and also avoid risk of producing freemartins. Finally, it may be beneficial to use in-vitro culture systems and the polymerase chain reaction to assess the effects of different procedures upon the efficiency of gene integration in farm animals. While this would be expensive in time and effort it would avoid the costs of large numbers of farm animals and could provide an extremely useful increase in efficiency.

A simple approach to gene transfer has been described (Lavitrano et al., 1989). It was reported that transgenic mice were obtained when spermatozoa were incubated in the presence of DNA for a period of $30 \mathrm{~min}$ before use for in-vitro fertilization. Two-cell embryos were transferred to the oviducts of pseudopregnant females. The plasmid (pSV2CAT) contained sequences derived from SV40, with bacterial chloramphenicol acetyl transferase (CAT) as a reporter gene. Sequences specific to the gene were reported in $\sim 30 \%$ of the progeny tested (about 250 ) and the gene was transmitted to some offspring. CAT activity was detected, particularly in tissue from muscle and tail, but the level of enzyme activity was so low as to demand a prolonged incubation period. Similar results have been presented by the same group following the deposition of treated spermatozoa in the oviducts of pigs (Gandolfi et al., 1989). These results generated a great deal of interest and many attempts have been made to repeat the original observation with mice. Despite a considerable effort and the co-operation of the laboratory in Rome in supplying some of their ingredients, no more transgenic mice have been reported (Brinster et al., 1989b).

There are a number of aspects of the original results of Lavitrano et al. (I989) that require clarification, including the lack of repeatability and the occurrence of rearrangements. There is an independent observation which shows that DNA does enter spermatozoa, and can be carried into eggs, where a gene may be expressed (Brackett et al., 1971). The question then remains as to whether this approach is likely to achieve gene transfer, particularly as the frequency of integration 
after injection into the cytoplasm was very low (only 2 of 224 fetuses derived from 890 injected eggs were transgenic; Brinster et al., 1985). It has been suggested that retroviral particles in the oocyte may have been responsible for the insertion described by Lavitrano et al. (1989), and that differences in the retroviral activity of different colonies of the same (or different) strain(s) of mice might account for the failure to repeat the original result (Erickson, 1990). Another unexpected aspect of the original report was the apparent occurrence of the same rearrangement in the 5 lines of mice studied. While this could be the result of contamination of the test samples with a rearranged fragment, it has also been suggested that it could reflect the activity of retroviral sequences during integration (Erickson, 1990). At present it is difficult to assess the original result, but it is clear that a great deal of further work is required if the method is to be reliable.

Retroviral vectors might be expected to provide a more efficient means of gene transfer (Fig. 2). Retroviruses infect cells and then insert their genome into the chromosomes of the cell (Varmus, 1988). Recombinant vectors have been produced that retain the ability to insert themselves into chromosomes, but which are incapable of replication. In principle this should create a vector able to achieve integration in a large proportion of embryos while inserting only a single copy of the gene into each cell. In practice, the success rates in mice have not been high and further research is required. The use of retroviral vectors may also have other disadvantages. The limit to the length of DNA that can be inserted into the vector may be restrictive. As there is increasing evidence of the need for introns if full expression of a transgene is to be achieved, some genes of interest will be of considerable size (possibly in excess of $100 \mathrm{kbp}$ ). Secondly, in early trials viral sequences interfered with the regulation of expression of the transgene (Jaehner et al, 1985). While other results are encouraging (Wagner et al., 1985; Soriano et al., 1986) there is a need for further research to confirm that gene expression may be regulated appropriately. Thirdly, as the young will be chimaeric if integration occurs after the first cleavage, it will be necessary to produce a second generation before the effect of the gene can be assessed. Finally, there is public concern over the safety of such vectors and the danger of recombination events allowing replication of the viral sequences.
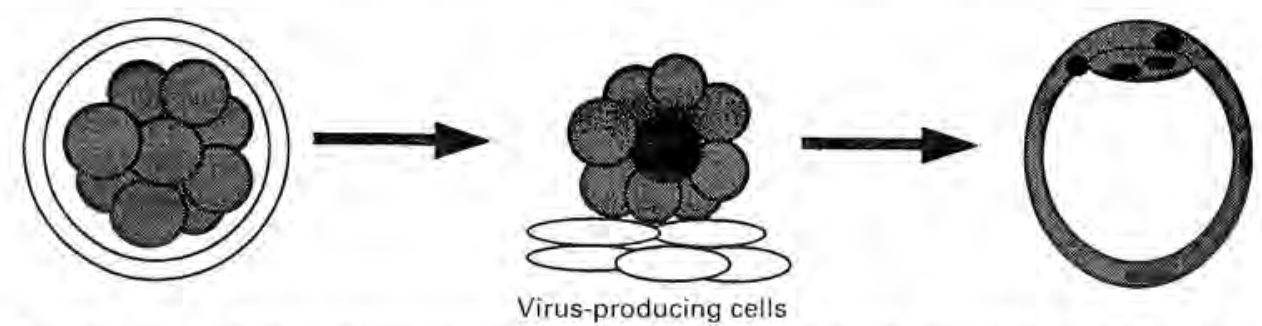

Fig. 2. Gene transfer by retroviral vector. Cleavage-stage embryos from which the zona pellucida has been removed are cultured with virus-producing cells. The recombinant viruses infect the cells of the embryo and the viral RNA is reverse transcribed into proviral DNA; the DNA sequences are then inserted into host cell DNA. After overnight co-culture, the embryos are transferred into the reproductive tract of foster mothers. As the proviruses lack sequences that direct the production of new virus the virus is not able to reproduce and spread to other cells. Alternatives to co-cultivation of embryos with virus-producing cells are microinjection of concentrated virus or of virus-producing cells under the zona pellucida. Transgenic animals are identified by analysis of DNA. Essentially all transgenic animals derived by this method will be mosaic; non-mosaic animals may be generated by breeding.

The random nature of the mechanism of integration of the gene has other implications for those wishing to exploit gene transfer. Damage to an existing gene was observed in some $8-10 \%$ of transgenic lines of mice (Palmiter \& Brinster, 1986). In production of animals for introduction into the general population, it will be necessary to confirm that site-directed mutation of this kind has not occurred by making homozygous animals for each transgenic line. This will impose costs and 
cause a delay in the use of such animals. At least as important is the effect of neighbouring DNA upon expression of the transgene. It is believed that this probably accounts for a large part of the variation between lines in the level of expression of the same transgene (Palmiter \& Brinster, 1986).

The final approach to germ-line manipulation exploits embryo stem cells as described by Notarianni et al. (1990c) (Fig. 3). Methods of culture of mouse embryos have been established such that cells derived from the inner cell mass divide, but do not differentiate (Evans \& Kaufman, 1981; Robertson, 1987). When injected into the blastocoele cavity of another embryo they of ten have the potential to contribute to all of the tissues of the offspring, including the germ line. The opportunity to manipulate and study the cells in culture before their transfer to recipient embryos confers several advantages. It is possible to apply methods of gene manipulation that have been developed for use with other tissue culture cells (Capecchi, 1989). As the efficiency of such procedures is commonly very low, of the order of 1 in 10000 cells transformed, it is impracticable to apply them to embryos. Selection allows the use of transformed cells and ensures that the desired change has been introduced into all offspring born. These methods are being used with mice to study early development (Joyner et al., 1989; Zimmer \& Gruss, 1989) and to create models of human diseases (Hooper et al., 1987).

At present gene transfer by direct injection is the only method of gene manipulation available in ruminants. Although it is inefficient and expensive it is being used in several different projects. It is probable that the methods will be improved and, in particular, that the development of methods of embryo stem cell culture and manipulation will create many more opportunities. The recent development of normal young following the transfer of nuclei from cells of the inner cell mass in sheep (Smith \& Wilmut, 1989) provides encouragement that it may become possible to transfer nuclei from modified embryo stem cells; this would provide an extremely efficient means of making genetic change.

\section{Control of gene expression}

Gene expression is determined by regulatory mechanisms that act at different levels. These serve to transcribe the gene in the right tissue at the appropriate stage of development, process and regulate the half-life of the mRNA, control its translation and determine the final site of production of the protein. The precise molecular mechanisms underlying many of these processes are not well understood at present. However, it is important that knowledge in this area improves to meet the requirement to design reliable transgenes that have precisely tailored patterns of expression. Some of the important regulatory interactions that are considered are indicated schematically in Fig. 4.

Distinct cis sequence motifs present within the DNA of the gene and its flanking regions contain the information that mediates the binding and interaction of trans-acting regulatory molecules (Fig. 4A). Transcription of a gene by DNA polymerase II requires the assembly of active transcription complexes at the $5^{i}$ end of the gene. This process involves the binding of general transcription factors to DNA sequences close to the transcriptional start of the gene. This region is termed the promoter and for many genes is characterized by short specific DNA sequences (e.g. the 'TATAA' and 'CAAT' boxes; Breathnach \& Chambon, 1981) which are now known to mediate the binding of the transcription factors.

General transcription factors are essential for gene function. They form part of the transcription complex and control its assembly and progression along the gene. These factors and their corresponding cis DNA elements are held in common between many different genes. Another class of regulatory interaction necessary for gene function involves factors that determine the expression of specific genes. Such interactions are mediated by sequence elements termed enhancers or response elements, They bind specific regulatory proteins, although precisely how such gene-specific interactions regulate the general transcriptional machinery is still not well understood. In a number of cases such elements have been precisely defined. For example, in the $5^{\prime}$ flanking region of the 


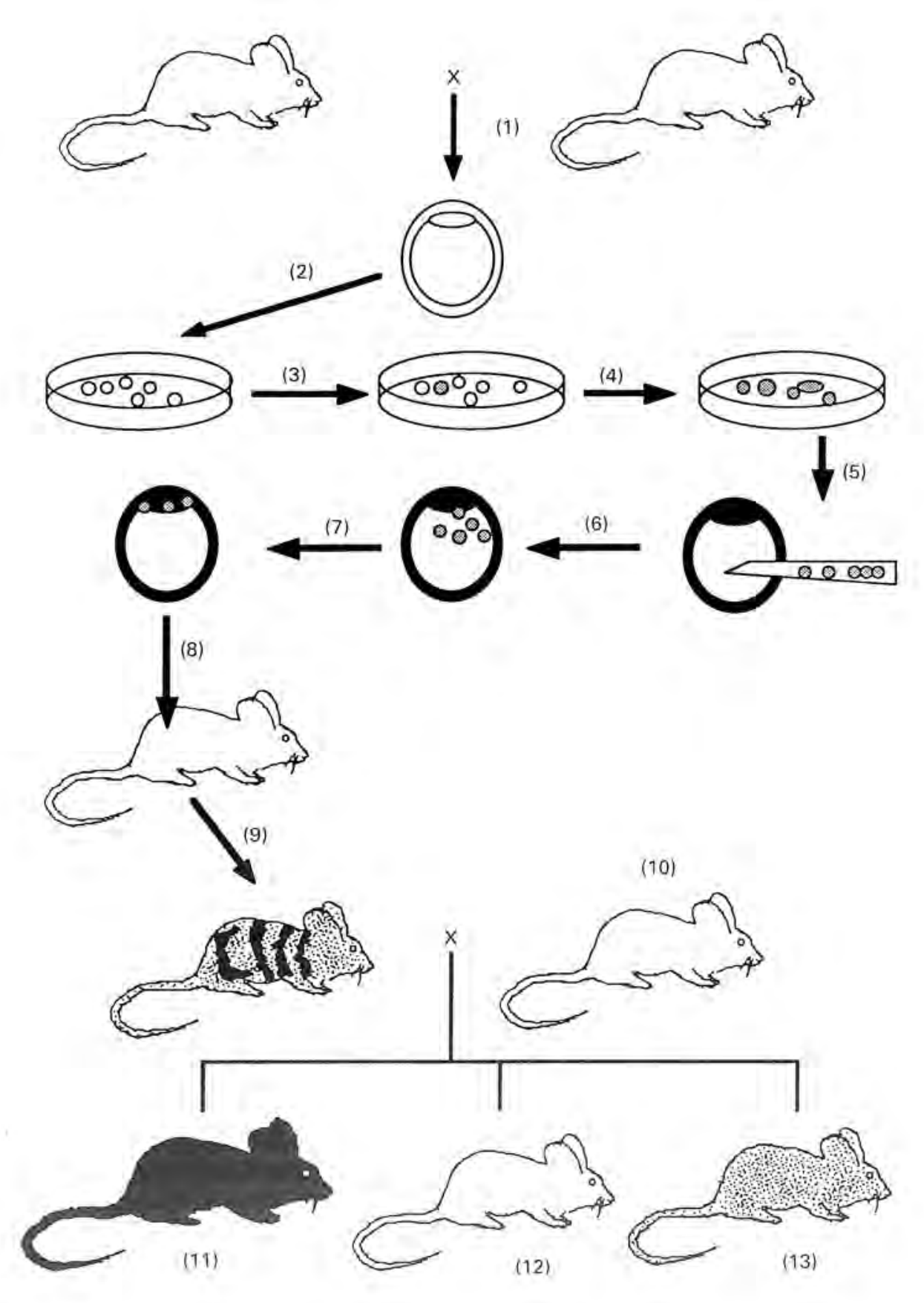


human metallothionein-IIA gene two distinct response elements have been defined which can confer inducibility by glucocorticoid or heavy metals, when linked to heterologous promoters (Karin et al., 1984).

Enhancer elements may be found closely associated with the promoter region, within introns or in regions quite distant from genes; e.g. the albumin enhancer, necessary for efficient liver-specific expression of transgenes, is located some $10 \mathrm{kbp}$ upstream of the site of transcriptional initiation of the albumin gene (Pinkert et al., 1987). Although in some cases precise interactions between enhancer sequences and specific transcription factors have been demonstrated (e.g. Sorger \& Pelham, 1988), it is becoming clear that the same enhancer sequence may bind a variety of trancription factors and, also, that subtle differences of the same transcription factor (for example in the degree of phosphorylation) may exist and determine quite different binding specificities (Sorger \& Pelham, 1988; Berk \& Schmidt, 1990). Finally, and as a general rule, it is the combination of various cis control elements and their corresponding trans-acting factors that determines a particular pattern of expression.

Early experiments with transgenic mice showed that, although transferred genes were often expressed with the expected pattern of tissue-specificity, indicating that both general and specific cis elements were present, the level of expression was often extremely unpredictable (for review, Palmiter \& Brinster, 1986). This variability has been termed the position effect and is thought to be caused by sequences at the site of integration of the transgene. It has been shown that some genes, most notably the globin genes, are linked to distant DNA elements which overcome the position effect (Grosveld et al., 1987), Constructs carrying these regions, termed dominant control regions (DCRs) are always expressed in erythroid cells in a position independent manner and at levels approaching the expression of the endogenous globin genes.

Fig. 3. Strategy for germ-line manipulation using embryonic stem (ES) cells. Shading patterns are used to indicate mice or embryos of different genotypes or the introduction of genetic change. Blastocysts from an inbred mouse strain homozygous for récessive mutations which produce a light coat colour are isolated (1) and used to derive a male ES cell line (2). ES cells are modified by techniques such as gene targeting (3) and the cells with the desired change (shown stippled) are identified or selected to provide a population of cells, each of which has the modification (4). These cells are then introduced into the blastocoele cavity of a blastocyst of a dark coat-colour genotype (5) where the ES cells colonize the inner cell mass ( 6 and 7). The injected blastocyst is then transferred to the uterus of a surrogate mother (8) and allowed to develop to term, producing a chimaera (9). These animals have cells derived from two embryos: those from the strain with the dark coat colour and cells from the strain with the light coat colour from which the ES cells were derived and into which the genetic change has been introduced. Male chimaeras are tested for germ-line chimaerism by mating to a female of the strain originally used to derive the ES cell line (10). Three types of mice may be born. Progeny resulting from fertilization by host blastocyst-derived spermatozoa show the dominant, dark coat colour (11) while those produced by ES cell-derived spermatozoa show the recessive light coat colour (12 and 13). Half (statistically) of all offspring derived from the ES cells have the modification on one of a pair a chromosomes, these individuals being identified by Southern blotting of DNA obtained by tail biopsy (13).

Because the same strain is used for both ES cell isolation and mating to the chimaera, heterozygous offspring are coisogenic with this strain, i.e. they carry the genetic modification on the same inbred background. Coisogenic homozygotes can be derived from the heterozygotes by standard animal breeding. In the special case of mutations on the X chromosome, all the first-generation female ES cell-derived progeny of the chimaera are heterozygous and all males wild-type. A useful strategy in this situation is to mate female heterozygotes back to the chimaera, since progeny of the chimaera's ES cell-derived spermatozoa can again be identified by coat colour and will, in the absence of any lethality, include homozygous mutant females. and hemizygous mutant males. 
A

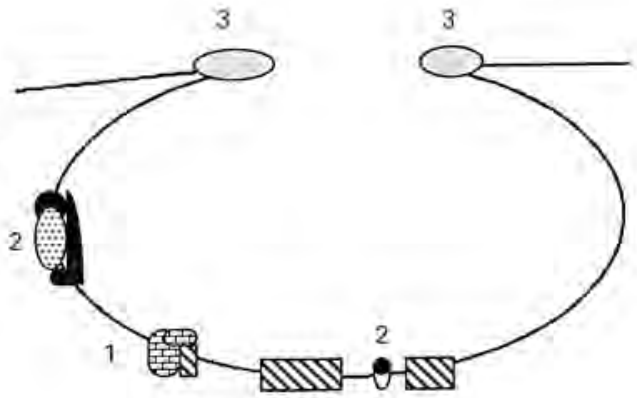

B

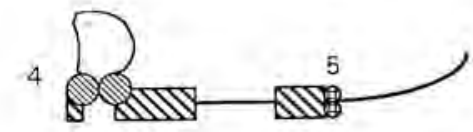

C

D

E
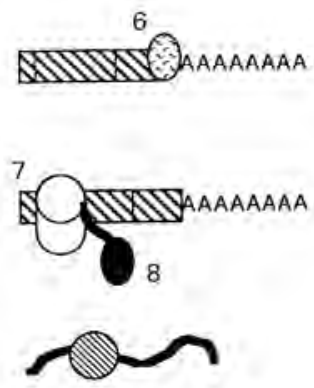

$1 \searrow^{9}$
KEY
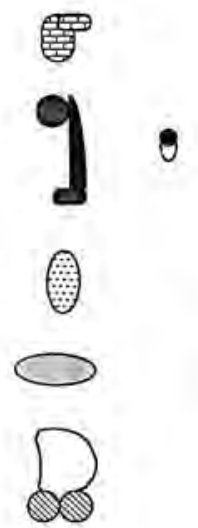

甲

Polyadenylation motif

Protein recognition site

Kosack consensus sequence

Signal peptide

Protein recognition site

Fig. 4. Schematic illustration of levels of control of gene expression. Exons are indicated by the hatched boxes and introns and flanking DNA sequences by continuous lines. (A) Transcription. Regulation of transciption is achieved by binding of a variety of factors to the promoter region and enhancer elements: (1) the assembly of the active transcription complex in the promoter region; (2) enhancer interactions often occur at a region outside the classical promoter, may involve many different factors and often form the basis of tissue-specific expression; (3) interactions with the nuclear matrix may determine the chromatin configuration of the gene thus making it accessible to soluble transcription factors. (B) RNA processing. (4) Introns are removed from the primary transcription product within the nucleus. Note that some genes contain enhancer sequences within introns and, also, that the presence of introns may be obligatory for efficient expression of some transgenes; (5) polyA tracts are added to nuclear RNA. (C) Export and stability. (6) mRNAs must be exported from the nucleus to the cytoplasm. They may be bound specifically to proteins that confer stability or, alternatively, may contain specific sequence motifs that ensure they are degraded. (D) Translation. (7) mRNAs are assembled into polyribosome and translated into proteins (thick line). The start of protein translation along the mRNA molecule is determined by the position of the first methionine (AUG) and efficient translation mediated by sequences within this region at the 5 end of the RNA molecule; (8) the presence of a signal peptide targets the polyribosome to the rough endoplasmic reticulum. (E) Protein targeting. (9) In some cases amino acid sequences determine the stability and fate of the newly synthesized protein.

The mechanism by which the globin DCR overcomes the position effect is not understood although it is clear that this region of DNA binds a variety of erythroid-specific factors. Another element, derived from the chicken lysozyme gene, has also been shown to overcome the position effect when incorporated into constructs (Stief et al., 1989). This element has been shown to 
specifically bind elements of the nuclear matrix and so termed a matrix attachment region (MAR). It has been suggested that the MAR may function by ensuring the correct folding or looping of the chromosome domain in which the gene is located so that it is accessible to general and specific transcription factors present in the nucleus (Gasser \& Laemmli, 1987).

The mechanisms regulating transcription are complex, and clearly this is a crucial level of gene control that must be considered in the design of transgenes. Defining the appropriate cis elements and including them in constructs for gene transfer has been sufficient to ensure expression in some cases. Although less immediately apparent, post-transcriptional controls also play their part in controlling gene expression and, as such, it may also be necessary to consider them with regard to transgene design.

After transcription the primary nuclear transcript is processed by the removal of introns and the addition of polyA sequences at the $3^{\prime}$ terminus (Fig, 4B). In general, these processes are not gene-specific (note, however, that there are a number of examples of tissue-specific patterns of genesplicing) although it is essential to incorporate into any gene construct the cis sequence elements (splice sites; polyA addition sites) that govern these processes. Many genes have been isolated as cDNA sequences (cloned by means of reverse transcriptase from tissue RNA) and, consequently, transgenes into which they have been incorporated may not require splicing. However, it does appear that introns may be necessary for the efficient expression of foreign genes in transgenic animals (Brinster et al., 1988; C. B. A. Whitelaw, M. McClenaghan, A. Archibald, S. Harris, J. P. Simons \& A. J. Clark unpublished) and that this requirement is not related to losing essential enhancer sequences present in a particular intron. This requirement of introns for efficient expression is not understood but, if of general applicability, has important consequences for transgene design.

Mature messenger RNA is exported from the nucleus and may interact with a variety of cytoplasmic factors (Fig. 4C). Some of these interactions serve to determine the half-life of a particular mRNA species. Special structures determined by sequences within mRNA molecules lead to recognition by the ribonucleases. For example, transferrin receptor mRNA contains in the 3 untranslated region a sequence that promotes rapid decay in the presence of iron (Mullner \& Kuhn, 1988). In the case of $\beta$-tubulin, sequence elements that mediate the stability of the mRNA in response to the concentration of unpolymerized subunits are located within the coding sequences at the 5 ' end of the mRNA (Gay et al., 1987).

For protein synthesis mRNAs are assembled into polyribosomes (Fig. 4D). The binding of mRNA to the ribosomal subunits and the assembly of the translational complex involves an interaction with sequences around the site of translational initiation in the mRNA. For certain genes it has been shown that other, specific, sequence motifs may influence the efficiency of the translational machinery. For example, within the $3^{\prime}$ untranslated region of the mRNA that encodes the human ferritin $\mathrm{H}$ chain are elements which specifically regulate the efficiency of translation (Roualt et al., 1988).

The amino acid sequence of proteins also contains regulatory information determining, for example, the mechanisms whereby they are targeted to and translocated across the correct intracellular membranes within the cell (Fig. 4E). One of the best understood processes governs the targeting and translocation machinery of the endoplasmic reticulum. Secretory proteins, lysosomal proteins and certain classes of integral membrane proteins contain a signal sequence, usually located at the $\mathrm{N}$ terminal of the protein, which provides an 'address' to the translocation machinery in the endoplasmic reticulum and ensures that the protein is synthesized into the lumen of the endoplasmic reticulum (Walter et al., 1984). Once in the lumen of endoplasmic reticulum the proteins need to be sorted, e.g. a distinction must be made between exported proteins and endogenous proteins, and recently it has been shown the amino acid sequence motif lysine-aspartic acid-glutamic acid-leucine mediates retention of luminal endoplasmic reticulum proteins (Pelham, 1989). Localized amino acid composition may also determine the stability of certain proteins and a common feature of many proteins with short intracellular half-lives $(<2 h)$ is the presence of one or more regions rich in proline, glutamic acid, serine and threonine (Rogers et al., 1986). 
The mechanisms controlling expression of genes act at various levels within the cell. Although the precise nature of many of these regulatory processes is poorly understood, the incorporation of the appropriate cis sequence elements that mediate them enables the construction of transgenes with defined patterns of expression. For the most part transgene design has concentrated upon manipulating those elements that regulate the transcription of genes but, for the future, greater flexibility in transgene function may be achieved by manipulating gene regulation at other levels such as mRNA stability, translational efficiency or protein stability. As the understanding of these various regulatory processes advances, so will the ability to harness them to control the expression of transgenes improve. Finally, the development of gene-targeting techniques will enable specific alterations to be made to the cis control elements of endogenous genes, at whatever level of gene control is appropriate, enabling the precise molecular tailoring of their expression.

\section{References}

Berk, A.J. \& Schmidt, M.C. (1990) How do transcription factors work? Genes and Development 4, 151-155.

Biery, K.A., Bondioli, K.R. \& DeMayo, F.J. (1988) Gene transfer by pro-nuclear injection in the bovine. Theriogenology 29, 224, abstr.

Brackett, B.G., Baranska, W., Sawaski, W. \& Koproski, H. (I971) Uptake of heterologous genome by mammalian spermatozoa and its transfer to ova through fertilisation. Proc natn. Acad. Sci. USA 68, 353-357.

Breathnach, R. \& Chambon, P. (1981) Organisation and expression of eucaryotic split genes coding for proteins. Ann. Rev, Biochem. 50, 349-383.

Brinster, R.L., Chen, H.Y., Trumbauer, M.E., Yagle, M.K. \& Palmiter, R.D. (1985) Factors affecting the efficiency of introducing foreign DNA into mice by microinjection eggs, Proc. nutn. Acad. Sci. USA 82, $4438-4442$.

Brinster, R.L., Allen, J.M., Behringer, R.R., Gelinas, R.E. \& Palmiter, R.D. (1988) Introns increase transcriptional efficiency in transgenic mice. Proc. natn. Acad. Sci. USA 85, 836-840.

Brinster, R.L., Braun, R.E., Lo, D., Avarbock, M.R., Oram, F. \& Palmiter, R.D. (1989a) Targeted correction of a major histocompatibility class $11 \mathrm{E}_{a}$ gene by DNA microinjected into mouse eggs. Proc: natn. Acad. Sci. USA 86, 7087-7091.

Brinster, R.L., Sandgren, E.P., Behringer, R.R. \& Palmiter, R.L. (1989b) No simple solution for making transgenic mice. Cell 59, 239-241.

Capechi, M.R. (1989) The new mouse genetics: altering the genome by gene targeting. Trends Genet. 5, 70-76.

Erickson, R.P. (1990) Are intermediate vectors needed between foreign DNA on sperm and the nucleus? Trends in Genetics 6, 31.

Evans, M.J. \& Kaufman, M.H. (1981) Establishment in culture of pluripotential cells from mouse embryos. Nature, Lond 292, 154156.

Gandolfi, F., Lavitrano, M., Camaioni, A., Spadafora, C., Siracusa, G. \& Lauria, A. (1989) The use of spermmediated gene transfer for the generation of transgenic pigs. J. Reprod. Fert., Abstr. Ser. 4, 16, abstr.

Gasser, S.M. \& Laemmli, U.K. (1987) A glimpse at chromosomal order. Trends in Genet, 3, 16-22.

Gay, D.A., Yen, T.J., Lau, J.T.Y. \& Cleveland, D.W. (1987) Sequences that confer $\beta$-tubulin autoregulation through modulated $m R$ NA stability reside within exon 1 of a $\beta$-tubulin mRNA. Cell 50, 671-679.
Gordon, I. \& Lu, K.H. (1990) Production of embryos in vitro and jts impact on livestock production. Theriogenology 33, 77-87.

Grosveld, F., van Assendelft, G.B., Greaves, D.R. \& Kollias, G. (1987) Position-independent, high-level expression of the human $\beta$-globin gene in transgenic mice. Cell 51, 975-985.

Hammer, R.E., Pursel, V.G., Rexroad, C.E., Jr, Wall, R.J., Bolt, D.J., Ebert, K.M., Palmiter, R.D. \& Brinster, R.L. (1985) Production of transgenic rabbits, sheep and pigs by microinjection. Nature. Lond. $315,680-683$.

Hooper, M.L., Hardy, K., Handyside, A., Hunter, S. \& Monk, M. (1987) HPRT-deficient (Lesch-Nyhan) embryos derived from germline colonisation by cultured cells, Nature, Lond 326, 292-295.

Jaehner, D., Kirsten, H., Mulligan, R. \& Jaenisch, R. (1985) Insertion of the bacterial gpt gene into the germ line of mice by retroviral infection, Proc nain. Acad. Sci. USA 82, 6927-6931.

Joyner, A. L., Skarnes, W.C. \& Rossant, J. (1989) Production of a mutation in mouse En-2 gene by homologous recombination in embryonic stem cells. Nature, Lond. 338, 153-156.

Karin, M., Haslinger, A., Holtgreve, H., Richards, R.I., Krauter, P., Westphal, H.M. \& Beato, M. (1984) Characterisation of a heterologous promoter in response to dexamethasone and cadmium by metallothionein gene 5 flanking DNA. Cell 36, 371-379.

King, D. \& Wall, R.J. (1988) Identification of specific gene sequences in preimplantation embryos by genomic amplification: detection of a transgene. Molec: Reprod, Devel, 1, 57-62.

Lavitrano, M., Camaioni, A., Fazio, V. M., Dolci, S, Farace, M.G. \& Spadafora, C. (1989) Sperm cells as vectors for introducing foreign DNA into eggs: genetic transformation of mice. Cell 57, 717-723,

Lu, K.H., Gordon, I., McGovern, H. \& Gallagher, M. (1988) Production of cattle embryos by in vitro maturation and fertilisation of follicular oocytes and their subsequent culture in sheep. Theriogenology 29, 272 , abstr.

Mullner, E.W. \& Kuhn, L.C. (1988) A stem-loop in the 3 untranslated region mediates iron-dependent regulation of transferrin receptor mRNA stability in the cytoplasm. Cell 53, 815-825. 
Murray, J.D., Nancarrow, C,D., Marshall, J.T., Hazleton, I.G. \& Ward, K.A. (1989) Production of transgenic Merino sheep by microinjection of ovine metallotionein-ovine growth hormone fusion genes. Reprod. Fertil. Dev. 1, 147-155.

Ninomiya, T., Hoshi, M., Mizuno, A., Nagao, M. \& Yuki, A. (1989) Selection of mouse preimplantation embryos carrying exogenous DNA by polymerase chain reaction. Molec. Reprod. Devel. 1, 242-248.

Notarianni, E., Laurie, S., Moor, R.M. \& Evans, M.J. (1990a) Maintenance and differentiation in culture of pluripotential embryonic cell lines from pig blastocysts. I. Reprod. Fert. Suppl. 41, 51-56.

Notarianni, E., Laurie, S., Moor, R.M. \& Evans, M.J. (1990b) Derivation of pluripotential, embryonic cell lines from porcine and ovine blastocycts. Proc. $4 \mathrm{th}$ Wld Congr, Genetics Applied to Livestock Production, Edinburgh XIII, 58-64.

Notarianni, E., Galli, C., Laurie, S., Moor, R.M. \& Evans, M.J. (1990c) Derivation of pluripotent embryonic cell lines from the pig and sheep. J. Reprod. Fert., Suppl. 43, 255-260.

Palmiter, R.D. \& Brinster, R.L. (1986) Germline transformation of mice. A. Rev. Genet. 20, $465-499$.

Parrish, J.J., Susko-Parrish, J., Leibfried-Rutledge, M.L., Critser, E.S., Eyestone, W.H. \& First, N.L. (1986) Bovine in vitro fertilisation with frozen thawed semen. Theriogenology 25, 591-600.

Pelham, H. (1989) The selectivity of secretion: protein sorting across the endoplasmic reticulum. Biochem. Soc. Trans. 17, 795-802.

Pinkert, C.A., Ornitz, D.M., Brinster, R.L. \& Palmiter, R.D. (1987) An albumin enhancer located $10 \mathrm{~kb}$ upstream functions along with its promoter to direct efficient, liver-specific expression in transgenic mice. Genes and Development 1, 268-276.

Pursel, V.G., Pinkert, C.A., Miller, K.F., Bolt, D.J., Campbell, R.G., Palmiter, R.D., Brinster, R.L. \& Hammer, R.E. (1989) Genetic engineering of livestock. Science, NY 244, 1281-1288.

Robertson, E. (1987) Embryo-derived stem cell lines. In Teratocarcinomas and Embryonic Stem Cells-A Practical Approach, pp. 71-112. Ed. E. Robertson. IRL Press, Oxford.

Rogers, S., Wells, R. \& Rechsteiner, M. (1986) Amino acid sequences common to rapidly degraded proteins: the PEST hypothesis. Science, NY 234, 364-368.
Roualt, T.A., Hentze, M.W., Caughman, S.W., Harford, J.B. \& Klausner, R.D. (1988) Binding of a cytostolic protein to the iron-responsive element of human ferritin messenger RNA. Science, NY 241, 1207-1210.

Saiki, R.J., Gelfand, D.H., Stoffel, S., Scharf, S.J., Higuchi, R., Horn, G.T., Mullis, K.B. \& Erlich, H.A. (1988) Primer-directed enzymatic amplification of DNA with a thermostable DNA polymerase. Science, NY 239, 487-491.

Simons, J.P., Wilmut, I., Clark, A.J., Archibald, A.L., Bishop, J.O. \& Lathe, R. (I988) Gene transfer into sheep. Bio/Technology 6, 179-183.

Smith, L.C. \& Wilmut, I. (1989) Influence of nuclear and cytoplasmic activity on the development in vivo of sheep embryos after nuclear transfer. Biol. Reprod. 40, 1027-1035.

Sorger, P.K. \& Pelham, H.R.B. (1988) Yeast heat shock factor is an essential DNA-binding protein that exhibits temperature-dependent phosphorylation. Cell 54, 855-864.

Soriano, P., Cone, R.D., Mulligan, R.C. \& Jaenisch, R. (1986) Tissue-specific and ectopic expression of genes introduced into transgenic mice by retroviruses. Science, NY 234, 1409-1213.

Staigmiller, R.B. \& Moor, R.M. (1984) Competence of ovine oocytes matured outside the follicle Gamete Res. 9, 22I-229.

Stief, A., Winter, D.M., Straitling, W.H. \& Sippel, A.E. (1989) A nuclear DNA attachment element mediates elevated and position-independent gene activity. Nature, Lond. 341, 343-345.

Varmus, H. (1988) Retroviruses. Science, NY 240, 14271435.

Wagner, E.F., Vanek, M. \& Vennström, B. (1985). Transfer of genes into embryonal carcinoma cells by retrovirus infection: efficient expression from an internal promoter. $E M B O J / 4,663-666$.

Walker, S.K. (1989) Collection, culture and pronuclear microinjection of sheep zygotes. Ph.D. thesis, University of Adelaide, Australia.

Walter, P., Gilmore, R. \& Blobel, G. (1984) Protein translocation across the endoplasmic reticulum. Cell 38, $5-8$.

Zimmer, A. \& Gruss, P. (1989) Production of chimaeric mice containing embryonic stem (ES) cells carrying a homeobox Hox 1-1 allele mutated by homologous recombination. Nature, Lond. 338, 150-153. 